\title{
Completeness of excision and follow up cytology in patients treated with loop excision biopsy
}

\author{
A M Zaitoun, G McKee, M J Coppen, S M Thomas, P O G Wilson
}

\begin{abstract}
Aims-To assess the relation between the grade and the status of follow up cytology, the completeness of loop excision biopsies with cervical intraepithelial neoplasia (CIN), and the findings at follow up cytology, as well as the differences between complete and incomplete exclusion, using the odds ratio. Treatment failure was assessed.
\end{abstract}

Methods-1600 women with CIN (290 CIN1, 304 CIN2, 1006 CIN3) were followed for a minimum of six months and a maximum of 10 years. A database was created and comparisons performed. The mean age of the patients was 37 years.

Results-Excision was complete in over $84 \%$ of loops. Residual disease and recurrence of high grade dyskaryosis was more common in women with CIN 3 than CIN 2 or 1. No high grade dyskaryosis was seen in the fifth follow up smear in patients with CIN 1 and CIN 2. Residual, recurrent, and persistent disease was most common in patients with incompletely excised CIN at ectocervical and endocervical margins and deep margins of resection than in patients with completely excised CIN. The odds ratios were significantly higher in the women who had incomplete excision of CIN at ectocervical, endocervical, both ecto- and endocervical, and deep margins of resection compared with those with apparent complete excision of CIN lesions. One patient developed invasive squamous cell carcinoma 44 months after loop excision which showed CIN 3 invading endocervical crypts and extending to both ectocervical and endocervical margins of resection. Conclusions-At long term follow up, patients with CIN who have residual disease are at increased risk of persistent disease and should therefore be followed up regularly with cytology and colposcopy. The findings support national policy of returning women with treated CIN of any grade to normal recall after five years except for cases of CIN3 where excision was incomplete or equivocal. In these cases follow up with annual smear for $\mathbf{1 0}$ years is recommended.

(f Clin Pathol 2000;53:191-196)

Keywords: cervical cytology; cervical intraepithelial neoplasia

Loop excision biopsy, also known as LLETZ (large loop excision of the transformation zone), is the most common and popular method of treatment of cervical intraepithelial neoplasia (CIN). Loop biopsies are performed for both diagnostic and therapeutic purposes. ${ }^{1-7}$ Histological evaluation of the loop excision biopsy specimen is traditionally made by the grade of CIN, the status of the margins of resection, the presence or absence of CIN in endocervical crypts, the presence or absence of invasion and cervical glandular intraepithelial neoplasia, and any other associated pathology. Histology-cytology correlation of CIN in cervical biopsies has been reported previously. ${ }^{8}$ The reported post-treatment success rate is over $90 \%$ with no further dyskaryosis. ${ }^{9}{ }^{10}$ Certain factors have been associated with failure of treatment or recurrence of CIN. These include the presence of CIN at ectocervical and endocervical margins of resection, ${ }^{11}{ }^{12}$ involvement of endocervical glands, ${ }^{13-17}$ large CIN lesions, ${ }^{11}{ }^{18}$ depth of the loop, ${ }^{19}{ }^{20}$ high grade of $\mathrm{CIN},{ }^{21}$ and the age of the patient. ${ }^{22}$

The development of invasive carcinoma following treatment by loop excision biopsy is considered a failure of treatment. ${ }^{23-26}$ Shumsky et al found that inadequacy of excision and cytological follow up represent the most common causes of failure of treatment of loop excision biopsy. ${ }^{25}$

In the guidance published in $1992,{ }^{27}$ the NHS Cervical Screening Programme recommended returning treated women with negative follow up smears to normal recall after five years. The second edition ${ }^{28}$ of the guidance (1997) acknowledged that some may not wish to return to annual screening until the 10th anniversary of treatment, especially for those with a history of high grade CIN, as was common practice before the 1992 guidelines were published.

In this study we examined the prognostic implications of the grade of CIN and the completeness of excision with the status of follow up cytology and consider the national recommendations on following up treated lesions.

\section{Methods}

The histology and follow up cytology were analysed in 1600 women (mean age 37 years) treated with loop excision biopsy. Subjects were selected from patients undergoing follow up cytology for CIN from two districts in the South Thames Region. Patients had cytological examinations six months after treatment and, providing no abnormality was detected, at 12 monthly intervals thereafter to a maximum of 10 years.

All biopsies ( $\mathrm{n}=1600)$ with CIN (290 CIN1, 304 CIN2, 1006 CIN3) from two laboratories were fixed in $4 \%$ formol saline and each 
specimen was cut in parallel slices at a maximum thickness of 3-4 mm. ${ }^{29}$ All tissue blocks were identified by their clock face position and embedded. Their number varied between six and 24 according to the specimen size. Each block was cut at $4-5 \mu \mathrm{m}$ thick and was stained with haematoxylin and eosin (H\&E).

The histological features studied included the grade of CIN, completeness of excision with and without involvement of endocervical epithelium and crypts, and incomplete excision at ectocervical, endocervical, and deep margins of resection, either separately or in combination with deep involvement of the crypts. Patients who had cervical glandular intraepithelial neoplasia (CGIN) and invasive carcinoma were excluded from the study. All histology specimens were graded as either CIN1, CIN2, or CIN3. In cases where disagreement occurred between the reviewing pathologists, two grades were given and the higher grade was used for statistical analysis. Equivocal excision was reported if CIN extended close to the excisional margins of resection. In this study only a histologically confirmed CIN lesions were used for analysis.

A database was created on EPI INFO version 6 (Public Domain CDC, Atlanta, Georgia, USA) including details of the patients' precolposcopy cytology, colposcopy, colposcopy histology, loop excisional biopsies, and follow up cytology, together with the dates of reporting of all findings. The mean (SD) follow up period was 4.63 (2.24) years (minimum 0.55 years; maximum 10.02 years). Follow up cytology was classified as negative; borderline; mild, moderate, or severe dyskaryosis; or inadequate. The rate of residual, recurrent, or persistent disease was defined by the presence of an abnormal smear in relation to the total number of smears at the interval period. The age of each patient was calculated to the date of loop biopsy reporting. In this study, no comparison was made between large loop (LLETZ), small loop (LETZ ), or cone biopsy. In patients who had more than one loop excisional biopsy, the first biopsy was considered.

\section{STATISTICAL ANALYSIS}

To facilitate statistical analysis the SNOMED code was used for categorisation of histology and cytology. The difference between completely excised and incompletely excised loop biopsies in relation to the status of follow up cytology (residual, recurrence, persistent) was analysed using a $\chi^{2}$ test. Odds ratios, Cornfield 95\% confidence limits, and exact 95\% confi- dence limits are reported. A two tailed significance test was employed in this study.

DEFINITIONS

Residual lesion-the presence of borderline nuclear changes or dyskaryosis in follow up cytology within 12 months after treatment by loop excision biopsy.

Recurrent lesion - the presence of borderline nuclear changes or dyskaryosis in follow up smears, 12 months after treatment by loop excision biopsy in women with no residual lesion.

Persistent lesion-the presence of borderline nuclear changes or dyskaryosis in follow up smear(s) 12 months or more after treatment in women in whom the first follow up smear(s) had been positive, irrespective of the status of completeness of excision.

Low grade cytological abnormality - all smears with cytological diagnosis of borderline nuclear changes and mild dyskaryosis.

High grade cytological abnormality-all smears with cytological diagnosis of a moderate dyskaryosis, severe dyskaryosis and glandular neoplasia.

Time periods - In this study the duration of one month was equivalent to 30 days, the duration of one year was equivalent to 365.25 days.

Odds - if p (probability) is the expected recurrence in patients treated by loop biopsy that showed incomplete excision of CIN at one margin, then the odds in favour of recurrence is $p / 1-p: 1$. If $R$ is the non-expected recurrence in patients treated by loop biopsy that showed complete excision of CIN, then the odds of recurrence is $\mathrm{R} / 1-\mathrm{R}: 1$.

Odds ratio (OR) - The odds ratio of two odds is the odds of one group (incomplete excision) divided by the odds of another group (complete excision). This can be expressed as:

$$
\mathrm{OR}=\frac{\mathrm{P}}{(1-\mathrm{P})} \div \frac{\mathrm{R}}{(1-\mathrm{R})}
$$

which reduces to

$$
\frac{\mathrm{P} \times(1-\mathrm{R})}{\mathrm{P} \times(1-\mathrm{P})}
$$

\section{Results}

COMPLETENESS OF EXCISION IN RELATION TO ALL GRADES OF CIN

Table 1 shows the overall values for patients with total recovery (normal cytology on follow up) and abnormal cytology. The overall residual, recurrent, or persistent abnormality

\begin{tabular}{|c|c|c|c|c|c|c|c|c|c|}
\hline \multirow[b]{2}{*}{$\begin{array}{l}\text { Grade of } \\
\text { CIN }\end{array}$} & \multicolumn{3}{|c|}{ Complete excision } & \multicolumn{3}{|c|}{ Incomplete excision } & \multicolumn{3}{|c|}{ Equivocal excision } \\
\hline & $\begin{array}{l}\text { Number of } \\
\text { biopsies }\end{array}$ & $\begin{array}{l}\text { Incidence of } \\
\text { positive } \\
\text { cytology }\end{array}$ & $\begin{array}{l}\% \\
\text { Recovery }\end{array}$ & $\begin{array}{l}\text { Number of } \\
\text { biopsies }\end{array}$ & $\begin{array}{l}\text { Incidence of } \\
\text { positive } \\
\text { cytology }\end{array}$ & $\begin{array}{l}\% \\
\text { Recovery }\end{array}$ & $\begin{array}{l}\text { Number of } \\
\text { biopsies }\end{array}$ & $\begin{array}{l}\text { Incidence of } \\
\text { positive } \\
\text { cytology }\end{array}$ & $\begin{array}{l}\% \\
\text { Recovery }\end{array}$ \\
\hline CIN2 & 188 & $10(5.3 \%)$ & 94.7 & 50 & $14(28 \%)$ & 72 & 32 & $12(37.5 \%)$ & 62.5 \\
\hline CIN3 & 433 & $29(6.7 \%)$ & 93.3 & 386 & $60(15.5 \%)$ & 84.5 & 58 & $19(32.8 \%)$ & 67.2 \\
\hline $\begin{array}{r}\mathrm{CIN} 2+ \\
\mathrm{CIN} 3\end{array}$ & 621 & $39(6.3 \%)$ & 93.7 & 436 & $74(17.0 \%)$ & 83 & 90 & $31(34.4 \%)$ & 65.6 \\
\hline
\end{tabular}

Table 1 Status of follow up cytology in relation to high grade CIN in loop excision biopsies 

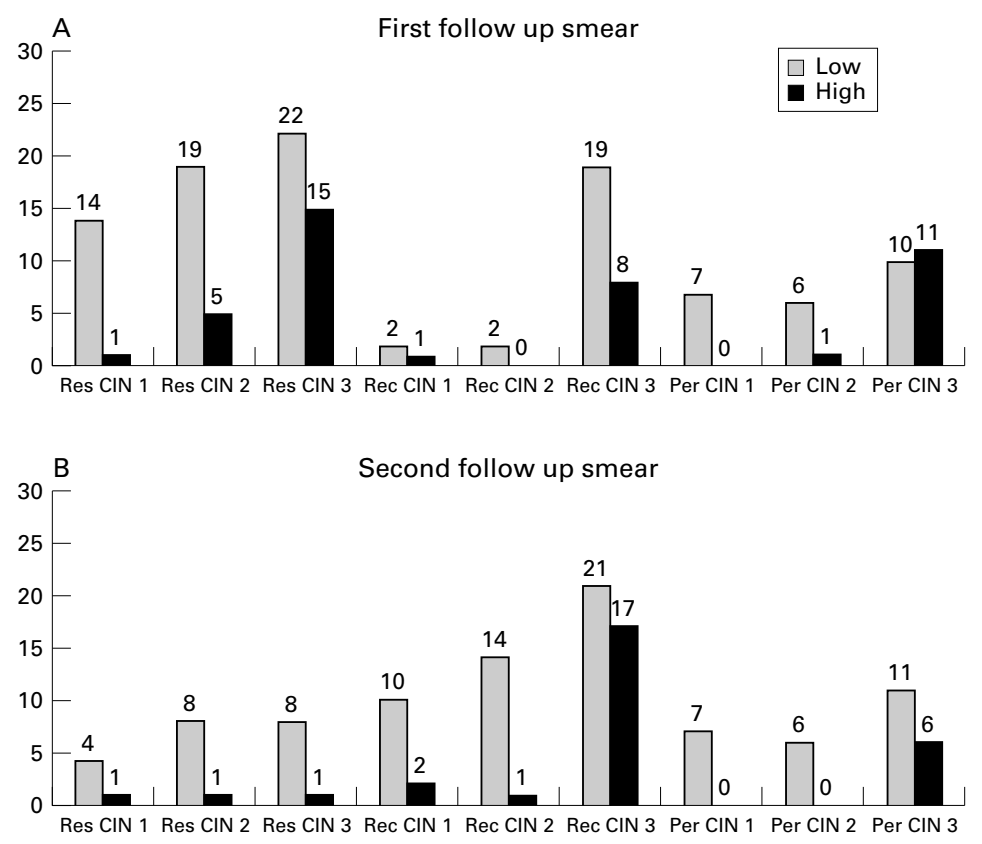

Figure 1 The grades of cytological abnormality (white bars, low grade; black bars, high grade) in the first $(A)$ and second (B) follow up smears. CIN, cervical intraepithelial neoplasia; Per, persistent; Rec, recurrence; Res, residual. The number of cases is shown.
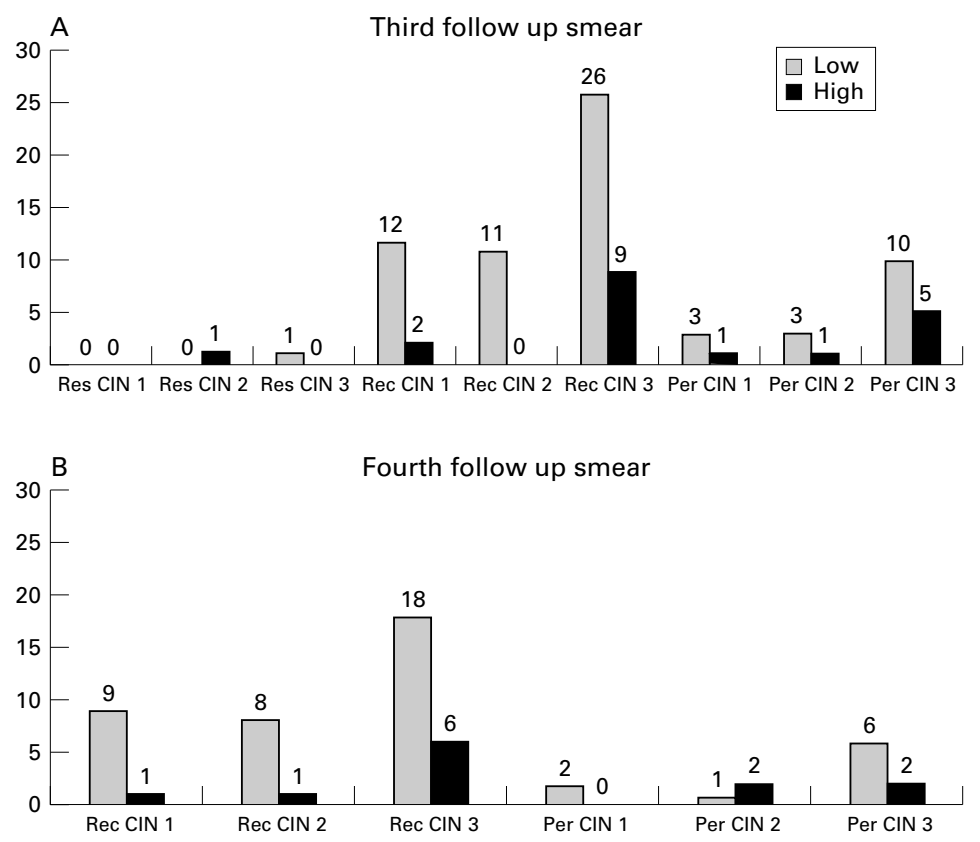

Figure 2 The grades of cytological abnormality (white bars, low grade; black bars, high grade) in the third $(A)$ and fourth (B) follow up smears. CIN, cervical intraepithelial neoplasia; Per, persistent; Rec, recurrence; Res, residual. The number of cases is shown.

was $6.3 \%$ in patients with completely excised CIN and $17.0 \%$ in patients with incompletely excised CIN in loop biopsies.

GRADE OF ABNORMAL FOLLOW UP CYTOLOGY AND THE STATUS OF RESIDUAL, RECURRENT, AND PERSISTENT DISEASE

Figures 1-3 illustrate the grades of abnormal cytology findings in relation to the status of residual, recurrent, or persistent in all grades of CIN. For residual status, high grade dyskaryosis in CIN 3 was five times more common than in CIN 2, and 15 times more common than in CIN 1 (fig 1A). For recurrent status, high grade dyskaryosis was six times more common in CIN 3 than in CIN 1 and CIN 2 (fig 1B). No high grade dyskaryosis was seen in the fifth follow up smear in women with CIN 1 and CIN 2 (fig 3A). None of the patients showed high grade abnormality in the sixth smear and thereafter (fig 3B). Women with persistent disease continued to have high grade abnormal cytology in all follow up smears (figs 2 and 3 ).

\section{COMPLETENESS OF EXCISION AND FOLLOW UP} CYTOLOGY

Table 2 shows the total number of patients and the percentages for completeness and incompleteness of excision in relation to the status of negative cytology, and residual, recurrent, and persistent disease in all grades of CIN. In all grades, residual recurrent and persistent disease was more common in patients with incompletely excised loops or where the excision was equivocal than in those with complete excision.

ODDS RATIOS FOR RESIDUAL, RECURRENT, AND PERSISTENT LESIONS IN RELATION TO COMPLETENESS OF EXCISION

Tables 3-5 show the odds ratios for incompletely excised loops in CIN1, CIN2, and CIN3 lesions, respectively. In patients with CIN1, a high grade of cytological abnormality was observed when ectocervical or endocervical margins were involved. In patients with CIN 2 who had residual disease, the odds ratio (8.9) was significantly higher in those who had incomplete excision than in those who had completely excised CIN (table 4). In the patients who had recurrent cytological abnormality the odds ratios were higher in those who had incompletely excised CIN at ectocervical, endocervical, and combined ectocervical and endocervical margins of resection than in those who had complete excision (table 4). In patients with CIN 3, all grades of residual, recurrent, and persistent disease were seen. More residual abnormality was seen in loops incompletely excised at the ectocervical margin, and more recurrent abnormality when endocervical margin was involved. In incompletely excised loops, for both ectocervical and endocervical margins, at deep margins and in equivocal excision, the risk of residual, recurrent, and persistent lesions was significantly higher than for completely excised loops.

CANCER OF CERVIX IN PATIENTS TREATED WITH LOOP EXCISION BIOPSY

A single case of invasive squamous cell carcinoma developed after treatment of CIN3 by loop biopsy (1/1006).

\section{Discussion}

Loop excision biopsy is the present method of choice for the management of patients with CIN. Long term follow up after loop excision biopsy is essential to detect a residual, recurrent, or persistent lesions. This is achieved by colposcopy, cytology, and histology. ${ }^{24}{ }^{17}$ In this study we chose cytology to assess the success rate, presence of residual disease, and 

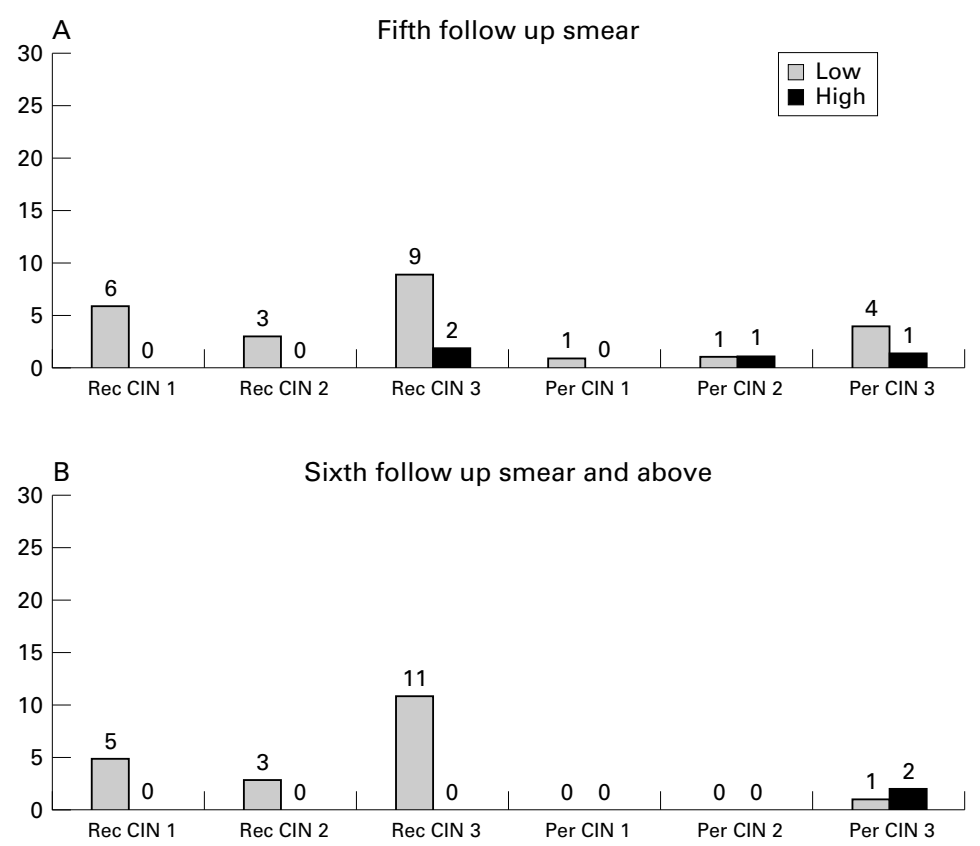

Figure 3 The grades of cytological abnormality (white bars, low grade; black bars, high grade) in the fifth (A) and sixth (B) follow up smears. CIN, cervical intraepithelial neoplasia; Per, persistent; Rec, recurrence; Res, residual. The number of cases is shown.

Table 2 Follow up cytology status in relation to completeness / incompleteness of excision in loop excision biopsies

\begin{tabular}{|c|c|c|c|c|c|c|c|c|}
\hline \multirow{2}{*}{$\begin{array}{l}\begin{array}{l}\text { Completeness of } \\
\text { excision }\end{array} \\
\text { CIN I }\end{array}$} & \multicolumn{2}{|c|}{ Negative } & \multicolumn{2}{|c|}{ Residual } & \multicolumn{2}{|c|}{ Recurrent } & \multicolumn{2}{|c|}{ Persistent } \\
\hline & & & & & & & & \\
\hline Completely excised & 179 & $(87.3 \%)$ & 5 & $(2.4 \%)$ & 16 & $(7.8 \%)$ & 5 & $(2.4 \%)$ \\
\hline $\begin{array}{l}\text { Incompleteley } \\
\text { excised }\end{array}$ & 12 & $(70.6 \%)$ & 2 & $(11.8 \%)$ & 3 & $(17.6 \%)$ & 0 & \\
\hline Equivocal & 31 & $(73.8 \%)$ & 4 & $(9.5 \%)$ & 4 & $(9.5 \%)$ & 3 & $(7.1 \%)$ \\
\hline \multicolumn{9}{|l|}{ CIN II } \\
\hline Completely excised & 178 & $(93.2 \%)$ & 5 & $(2.6 \%)$ & 4 & $(2.1 \%)$ & 1 & $(0.5 \%)$ \\
\hline $\begin{array}{l}\text { Incompleteley } \\
\text { excised }\end{array}$ & 36 & $(72 \%)$ & 4 & $(8 \%)$ & 6 & $(12 \%)$ & 4 & $(8 \%)$ \\
\hline Equivocal & 20 & $(62.5 \%)$ & 6 & $(18.8 \%)$ & 5 & $(15.6 \%)$ & 1 & $(3.1 \%)$ \\
\hline \multicolumn{9}{|l|}{ CIN III } \\
\hline Completely excised & 404 & $(93.3 \%)$ & 3 & $(0.7 \%)$ & 23 & $(5.3 \%)$ & 3 & $(0.7 \%)$ \\
\hline $\begin{array}{l}\text { Incompleteley } \\
\text { excised }\end{array}$ & 326 & $(84.5 \%)$ & 14 & $(3.6 \%)$ & 33 & $(8.5 \%)$ & 13 & $(3.4 \%)$ \\
\hline Equivocal & 39 & $(67.2 \%)$ & 6 & $(10.3 \%)$ & 7 & $(12.1 \%)$ & 6 & $(10.3 \%)$ \\
\hline
\end{tabular}

All grades of dyskaryosis are included as positive follow up cytology. CIN, cervical intraepithelial neoplasia.

Table 3 Odds ratios for incompleteness of excision compared with the status of follow up cytology in loop biopsies, CIN1

\begin{tabular}{llll}
\hline Incompleteness of excision & Odds ratio & Confidence interval & p Value \\
\hline Residual lesion & & & \\
Ectocervical margin & 11.93 & $0.19<\mathrm{OR}<177.02^{\star \star}$ & 0.012 \\
Endocervical margin & 8.95 & $0.15<\mathrm{OR}<114.03^{\star \star}$ & 0.030 \\
Glands & 0.00 & $0.00<\mathrm{OR}<58.60^{\star}$ & $\mathrm{NS}$ \\
Equivocal & 4.62 & $0.86<\mathrm{OR}<22.57^{\star \star}$ & 0.18 \\
Recurrent lesion & & & \\
Ectocervical margin & 7.46 & $0.57<\mathrm{OR}<68.85^{\star \star}$ & 0.014 \\
Endocervical margin & 0.00 & & $\mathrm{NS}$ \\
Glands & 0.00 & $0.38<\mathrm{OR}<5.09^{\star}$ & $\mathrm{NS}$ \\
Equivocal & 1.44 & & \\
Persistent lesion & & & $\mathrm{NS}$ \\
Ectocervical margin & 0.00 & & $\mathrm{NS}$ \\
Endocervical margin & 0.00 & $0.51<\mathrm{OR}<18.72$ & $\mathrm{NS}$ \\
Glands & 0.00 & 3.46 & $\mathrm{NS}$ \\
Equivocal & & & \\
\hline
\end{tabular}

Confidence limits used: ${ }^{\star}$ Cornfield $95 \%$ confidence limits; ${ }^{\star \star}$ Exact $95 \%$ confidence limits. CIN, cervical intraepithelial neoplasia.

recurrence of abnormality following loop excision biopsy.
We categorised the patients in relation to follow up cytology into four groups: first, those who had normal cytology on follow up; second, those who had residual disease within 12 months; third, those with recurrent disease after 12 months free from disease; and fourth (the smallest group), those who had residual disease and continued to have abnormality thereafter.

High success rates have been reported with loop excision biopsies for CIN. ${ }^{8-10}$ Our study showed a low incidence of residual or recurrent disease, also indicating a high success rate. The finding of higher residual and recurrent rates shown by high grade dyskaryosis (figs $1-3$ ) in patients with treated CIN3 than in those with CIN2 or CIN1 is consistent with previous studies. ${ }^{9}{ }^{17}{ }^{18}$ Our investigation also showed that persistent high grade cytology was found after the fifth follow up smear only in patients treated for CIN3. Therefore we maintain that patients with CIN3 with a residual lesion are at increased risk of persistent disease and so require careful long term follow up. In a recent study, Ho et al found that persistent genital papillomavirus infection was associated with the highest risk of persistent cervical dysplasia. ${ }^{30}$ However, such screening methods have as yet no place in the present routine follow up, in the face of the established reliability of cytology, colposcopy, and biopsy.

The extension of CIN into the ectocervical and endocervical margins is associated with a high risk of recurrence. This finding of our study is in agreement with results reported by others. ${ }^{11} 12$ In addition, we showed that in patients with CIN3, the risk of a residual lesion with incompletely excised loops was increased sixfold compared with the risk of recurrence when the ectocervical margin was involved (odds ratio $6.60 v 0.69$ ), while the risk of recurrence was higher than the risk of residual disease by a factor of 2 when the endocervical margin was involved (odds ratio $2.32 v 1.48$ ). The extension of CIN into the deep margin of resection was associated with the highest risk of residual, recurrent, and persistent lesions. This is in agreement with previous reports. ${ }^{13-17}$ Rasbridge et al found that a depth of involvement of crypts of $>1.7 \mathrm{~mm}$ was associated with recurrence of disease in 13 of 22 cases (59\%). ${ }^{15}$ In a recent study by Hulman et al, ${ }^{20}$ equivocal excision was associated with high recurrence rates. This agrees with our findings and indicates that cases where excision is equivocal should be considered as have a higher risk of recurrence.

Despite positive margins, only a small number of patients had residual and recurrent disease at follow up. Murdock et al found that when the ectocervical margins were positive, $7.7 \%$ had residual disease at follow up, compared with $9.4 \%$ with residual disease when the endocervical margins were involved and $35.7 \%$ if both margins were involved. ${ }^{2}$ Incompletely excised CIN by loop excision biopsy does not equate with residual disease. ${ }^{2}$ The results of our study confirm this concept. Explanations for this include post-biopsy inflammatory response, distortion of the speci- 
Table 4 Odds ratios for incompleteness of excision compared with the status of follow up cytology in loop biopsies, CIN2

\begin{tabular}{llll}
\hline Incompleteness of excision & Odds ratio & Confidence interval & p Value \\
\hline Residual lesion & & & \\
Ectocervical margin & 2.37 & $0.00<\mathrm{OR}<24.03^{\star}$ & $\mathrm{NS}$ \\
Endocervical margin & 5.09 & $0.00<\mathrm{OR}<59.45^{\star}$ & $\mathrm{NS}$ \\
Ecto- and endocervical margins & 8.90 & $0.15<\mathrm{OR}<113.40^{\star \star}$ & 0.03 \\
Glands & 3.56 & $0.00<\mathrm{OR}<38.42^{\star}$ & $\mathrm{NS}$ \\
Equivocal & 10.68 & $2.42<\mathrm{OR}<47.60^{\star \star}$ & 0.00001 \\
& & & \\
Recurrent lesion & 5.93 & $0.49<\mathrm{OR}<44.73^{\star \star}$ & 0.03 \\
Ectocervical margin & 12.71 & $0.96<\mathrm{OR}<104.51^{\star \star}$ & 0.0008 \\
Endocervical margin & 11.13 & $0.00<\mathrm{OR}<169.63^{\star}$ & 0.02 \\
Ecto- and endocervical margins & 4.45 & $0.08<\mathrm{OR}<50.28^{\star \star}$ & $\mathrm{NS}$ \\
Glands & 11.13 & $2.15<\mathrm{OR}<59.58^{\star \star}$ & 0.00004 \\
Equivocal & & & \\
Ectocervical margin & 0.00 & & $\mathrm{NS}$ \\
Persistent lesion & 50.86 & & 0.0000005 \\
Endocervical margin & 44.50 & & 0.00004 \\
Ecto- and endocervical margins & 17.80 & & 0.007 \\
Glands & 8.90 & & $\mathrm{NS}$ \\
Equivocal & & & \\
\hline
\end{tabular}

Confidence limits used: ${ }^{\star}$ Cornfield $95 \%$ confidence limits; ${ }^{\star \star}$ Exact $95 \%$ confidence limits. CIN, cervical intraepithelial neoplasia.

Table 5 Odds ratios for incompleteness of excision compared with the status of follow up cytology in loop biopsies, CIN3

\begin{tabular}{llll}
\hline Incompleteness of excision & Odds ratio & Confidence interval & p Value \\
\hline Residual lesion & & & \\
Ectocervical margin & 6.60 & $1.25<\mathrm{OR}<42.99^{\star \star}$ & 0.004 \\
Endocervical margin & 1.48 & $0.03<\mathrm{OR}<18.65^{\star \star}$ & $\mathrm{NS}$ \\
Ecto- and endocervical margins & 8.69 & $0.69<\mathrm{OR}<77.97^{\star \star}$ & 0.006 \\
Glands & 4.49 & $0.59<\mathrm{OR}<33.92^{\star \star}$ & 0.05 \\
Deep margin & 33.67 & $3.95<\mathrm{OR}<268.80^{\star \star}$ & 0.00000000 \\
Equivocal & 20.72 & $4.17<\mathrm{OR}<130.95^{\star \star}$ & 0.00000001 \\
Echar & & & \\
Ectocervical margin & & & \\
Endocervical margin & 0.69 & $0.20<\mathrm{OR}<2.18^{\star}$ & $\mathrm{NS}$ \\
Ecto- and endocervical margins & 2.32 & $1.04<\mathrm{OR}<5.12^{\star}$ & 0.02 \\
Glands & 2.83 & $0.87<\mathrm{OR}<8.68^{\star}$ & 0.04 \\
Deep margin & 1.17 & $0.41<\mathrm{OR}<3.17^{\star}$ & $\mathrm{NS}$ \\
Equivocal & 8.78 & $2.63<\mathrm{OR}<28.61^{\star}$ & 0.000003 \\
& 3.15 & $1.14<\mathrm{OR}<8.44^{\star}$ & 0.009 \\
Persistent lesion & & & \\
Ectocervical margin & 3.96 & $0.52<\mathrm{OR}<29.90^{\star \star}$ & $\mathrm{NS}$ \\
Endocervical margin & 4.44 & $0.58<\mathrm{OR}<33.55^{\star \star}$ & 0.049 \\
Ecto- and endocervical margins & 4.34 & $0.08<\mathrm{OR}<55.62^{\star \star}$ & $\mathrm{NS}$ \\
Glands & 5.99 & $0.99<\mathrm{OR}<41.36^{\star \star}$ & 0.009 \\
Deep margin & 22.44 & $1.68<\mathrm{OR}<209.52^{\star \star}$ & 0.000004 \\
Equivocal & 20.72 & $4.17<\mathrm{OR}<130.95^{\star \star}$ & 0.00000001 \\
\hline
\end{tabular}

Confidence limits used: ${ }^{\star}$ Cornfield $95 \%$ confidence limits; ${ }^{\star \star}$ Exact $95 \%$ confidence limits. CIN, cervical intraepithelial neoplasia.

men margins, and induced alteration in the natural history of CIN disease. Other possible factors include regression of the disease and error in pathology reporting at histological and cellular levels. ${ }^{30-32}$

Residual preinvasive disease increases the risk of subsequent invasive carcinoma ninefold compared with cases where there is no evidence of residual disease. ${ }^{22}$ The incidence of invasive carcinoma after loop excision biopsy ranges from $0.2 \%$ to $0.4 \% .^{23-26}$ In the present study, only one patient with positive ectocervical and endocervical margins with residual disease developed invasive carcinoma. The primary aim of patient follow up is to ensure adequate detection of residual or recurrent disease before progression to invasive carcinoma.

The use of excision techniques is the mainstay of management of CIN. These techniques include cold knife biopsy, laser cone biopsy, large loop diathermy, and hysterectomy. ${ }^{8}{ }^{21}$ In this audit no comparison was made between the techniques used in loop excision or between operators in our hos- pitals. It is likely that the proportion of cases where CIN is incompletely excised varies from centre to centre, depending on the skill, experience, and procedural preferences of colposcopy staff. There is currently no achievable standard published against which this can be measured. We recommend that consideration be given to this, if and when the Standards and quality in colposcopy guidance ${ }^{35}$ is updated.

\section{CONCLUSIONS}

We conclude from this study that in patients treated with loop excision biopsy, the risk of residual, recurrent, and persistent disease was higher in CIN3 than CIN2 or CIN1. Relatively higher rates were also seen in incompletely excised compared with completely excised CIN. Involvement of ectocervical, endocervical, and deep margins and of crypts is associated with high risk of residual, recurrent, and persistent disease. In patients with CIN3, persistent disease may continue even after the fifth follow up smear. Residual, recurrent, and persistent disease was high in cases with equivocal excisions. Patients with incompletely excised loops with CIN3 should be followed up regularly to prevent the progression of CIN to invasive carcinoma.

This audit project was funded by the South Thames NHS Regional Quality Assurance Team.

1 Woodman CNJ, Jordan JA, Mylotte MJ, et al. The management of cervical intraepithelial neoplasia by coagulation electrodiathermy. Br f Obstet Gynaecol 1985;92:751-5.

electrodiathermy. Br $\mathcal{F}$ Obstet Gynaecol 1985;92:751-5.
2 Murdoch JB, Morgan PR, Lopes A, et al. Histological Murdoch JB, Morgan PR, Lopes A, et al. Histological
incomplete excision of CIN after large loop excision of the incomplete excision of CIN after large loop excision of the
transformation zone (LLETZ) merits careful follow up, not transformation zone (LLETZ) merits careful follow

3 Oyesanya OA, Amerasinghe CN, Manning EAD. Outpatient excisional management of cervical intraepithelial neoplasia. A prospective, randomized comparison between loop diathermy excision and laser excisional conization. $\mathrm{Am}$ f Obstet Gynecol 1993;168:485-8.

4 Hodges DJ. Loop excision of the transformation zone (LETZ) for cervical dysplasia - a review. FSOGC 1994;16: 2017-23.

5 Ferenczy A. Management of patients with high grade squamous intraepithelial lesions. Cancer 1995;76:1928-33.

6 Ferenczy A, Choukroun D, Arsenau J. Loop electrosurgical excision procedure for squamous intraepithelial lesions of the cervix: advantages and potential pitfalls. Obstet Gynecol the cervix: advanta

7 Matsura Y, Kawagoe T, Toki N, et al. Early cervical neoplasia confirmed by conisation: diagnostic accuracy of cytology, colposcopy and punch biopsy. Acta Cytol 1996;40:241-6

8 Jones, BA, Novis DA. Cervical biopsy-cytology correlation. A College of American Pathologists Q-Probe study of 22,439 correlations in 348 Laboratories. Arch Pathol Lab Med 1996;120:523-31.

9 Prendiville W, Cullimore J, Norman S. Late loop excision of the transformation zone (LLETZ). A new method of managing women with cervical intraepithelial neoplasia. $\mathrm{Br} F$ Obstet Gynaecol 1989;96:1054-60.

10 Hartman B, Kaplan B, Boone D. Morphometric analysis of dysplasia in cervical cone biopsy specimens in cases with false-negative cytology. Obstet Gynecol 1986;68:832.

11 Shafi MI, Dunn JA, Buxton EJ, et al. Abnormal cervical cytology following large loop excision of the transformation zone: a case controlled study. Br $\mathcal{F}$ Obstet Gynaecol

12 Anderson ES, Nielson K, Larsen G. Laser conisation: follow up in patients with cervical intraepithelial neoplasia in the cone margin. Gynecol Oncol 1990;39:328-31.

13 Anderson MC, Hartley RB. Cervical crypt involvement by intraepithelial neoplasia. Obstet Gynecol 1980;55:546-50.

14 Massad LS, Halperin CJ, Bitterman P. Correlation between colposcopically directed biopsy and cervical loop excision. Gynecol Oncol 1996;60:400-3.

15 Rasbridge SA, Jenkins D, Tay SK. A histological and immunohistological study of cervical intraepithelial neoplasia in relation to recurrence after local treatment. Br $\mathcal{F}$ Obstet relation to recurrence after

16 Demopoulos RI, Horowitz LF, Vamvakas EC. Endocervical gland involvement by cervical intraepithelial neoplasia grade III: predictive value for residual and/or recurrent disease. Cancer 1991;68:1932-6. 
17 Mahadevan N, Horwell DH. The value of cytology and colposcopy in the follow up of cervical intraepithelial neoplasia after treatment by laser excicion. Br f Obstet Gynaecol 1993;100:563-6.

18 Jarmulowicz MR, Jenkins D, Barton SE, et al. Cytological status and lesion size: a further dimension in cervical intraepithelial neoplasia. Br f Obstet Gynaecol 1989;96 1061-6.

19 Abdul-Karim FW, Fu YS, Reagan JW, et al. Morphometric study of intraepithelial neoplasia of the uterine cervix Obstet Gynecol 1982;60:210-14.

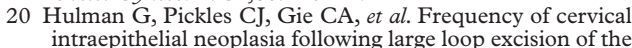
transformation zone. F Clin Pathol 1998;51:375-7.

21 Wright VC, Davies E, Riopelle MA. Laser surgery for cervical intraepithelial neoplasia: principles and results. $A m \mathcal{F}$ Obstet Gynecol 1983;154:181-4.

22 McIndoe WA, McLean MR, Jones R, et al. The invasive potential of carcinoma in situ of the cervix. Obstet Gynecol potential of carcin

23 Pearson SE, Whittaker J, Ireland D, et al. Invasive cancer of the cervix after laser treatment. Br 7 Obstet Gynaecol 1989 96:486-8.

24 Anderson MC. Invasive carcinoma of the cervix following local destructive treatment for cervical intraepithelia neoplasia. Br f Obstet Gynaecol 1993;100:657-63.

25 Shumsky AG, Stuart GCE, Nation J. Carcinoma of the cervix following conservative management of cervical intraepithelial neoplasia. Gynecol Oncol 1994;53:50-4.

26 Moreno V, Munoz N, Bosch FX, et al. Risk factors for progression of cervical intraepithelial neoplasm grade III to invasive cervical cancer. Cancer Epidemiol Biomarkers Prev 1995;4:459-67.
27 Duncan ID, ed. Guidelines for clinical practice and programme management. Oxford: NHS Cervical Screening programme, 1992

28 Duncan ID, ed. Guidelines for clinical practice and programme management, 2nd ed. Sheffield: NHS Cervical Screening Programme, 1997. [NHSCSP Publication No 8.]

29 29. Anderson MC. Premalignant and malignant disease of the cervix. In: Fox H, ed. Haines and Taylor obstetrical and gynaecological pathology, 3rd ed. Edinburgh: Churchill Livingstone, 1987:255-301.

30 Ho GYF, Burk RD, Klein S, et al. Persistent genital human papillomavirus infection as a risk factor for persistent cervical dysplasia. 7 Natl Cancer Inst 1995;87:1365-71.

31 Ostor AG. Natural history of cervical intraepithelial neoplasia: a critical review. Int $\mathcal{F}$ Gynecol Pathol 1993;12: 186-92.

32 Gardeil F, Barry-Walsh C, Prendiville W, et al. Persistent intraepithelial neoplasia after excision for cervical intraepithelial neoplasia grade III. Obstet Gynecol 1997;89:419-22.

33 Oyesanya OA, Amerasinghe C, Manning EAD. A comparison between loop diathermy conization and cold-knife conization for management of cervical dysplasia associated with unsatisfactory colposcopy. Gynecol Oncol 1993;50:84-8.

34 Keijser KGG, Kenemans P, Petronella J, et al. Diathermy loop excision in the management of cervical intraepithelial neoplasia: diagnosis and treatment in one procedure. $A m \mathcal{F}$ Obstet Gynecol 1992;166:1281-7.

35 Luesley D, ed. Standards and quality in colposcopy. NHS Cervical Screening Programme publication No 2. Sheffield, 1996. 